\title{
Corrosive Esophagitis and Gastritis Induced by Glutaraldehyde Ingestion
}

\author{
Donghwan Jun', Hye-Jin Kim², Hyun Suk Lee², Hong Jip Yoon², Jae Yong Park², Beom Jin Kim², Jae Gyu Kim² \\ Division of Gastroenterology, Department of Internal Medicine, Dongshin Hospital ${ }^{1}$, Division of Gastroenterology, Department of Internal \\ Medicine, Chung-Ang University College of Medicine², Seoul, Korea
}

\begin{abstract}
Corrosive esophagitis and gastritis are characterized by caustic damage due to ingestion of chemical agents. Caustic agents cause tissue destruction through liquefaction or coagulation reactions. Here, we report a case of corrosive esophagitis and gastritis caused by accidental ingestion of glutaraldehyde in Korea. A 62-year-old man presented to the emergency department 8 hours after ingesting glutaraldehyde, which is widely used for the prevention of foot-and-mouth disease in pigs. Urgent endoscopic examination revealed severely damaged mucosae of the esophagus and stomach. With conservative treatment, the patient's condition was improved, and he was discharged on the 35th day of admission. (Korean J Helicobacter Up Gastrointest Res 2020;20:237-242)
\end{abstract}

Key Words: Esophagitis; Gastritis; Glutaral; Caustics

\section{INTRODUCTION}

Acute corrosive injuries appear as a result of ingestion of acids, bases, oxidants, heavy metal salts and other chemical substances. They can cause various degrees of injuries to the upper gastrointestinal tract as well as aerodigestive system. Presenting symptoms may be dyspnea, hoarseness and dysphonia. And then those substances can cause additional injuries passing through the upper digestive tract, resulting in epigastric pain, vomiting, and hematemesis occasionally. Intensity of injury depends on the type, concentration, time of contact and amount of the substance ingested. Even after the patient survives the acute phase of the poisoning, following regenerative response may result in esophageal or gastric stenosis and increased risk for esophageal and gastric cancer. ${ }^{1}$ Early endoscopic intervention is useful in patients with corrosive poisoning, not only for assessing the degree of mucosal injury and severity, but also for determining the treatment plan and predicting prognosis. ${ }^{2}$ Glutaraldehyde is widely used for high-level disinfection of medical instruments, for its sterilizing effect and

Received: April 27, 2020 Revised: May 21, 2020 Accepted: May 29, 2020

Corresponding author: Jae Gyu Kim

Division of Gastroenterology, Department of Internal Medicine, Chung-Ang University College of Medicine, 84 Heukseok-ro, Dongjak-gu, Seoul 06974, Korea Tel: +82-2-6299-3147, Fax: +82-2-749-9150, E-mail: jgkimd@cau.ac.kr broad-spectrum biocidal activity. Moreover, it is also used for prevention of foot-and-mouth disease in pigs, in Korea. As far as we know, no cases of corrosive esophagitis and gastritis induced by glutaraldehyde ingestion have been reported in human. Here, we report the first case of corrosive esophagitis and gastritis caused due to ingestion of glutaraldehyde, with a favorable outcome achieved by conservative management.

\section{CASE REPORT}

A 62-year-old man presented to the emergency room with epigastric pain, nausea, vomiting, odynophagia and hoarseness, 8 hours after accidental ingestion of glutaraldehyde solution, which is used to prevent foot-andmouth disease in pigs. He mistook the solution for alcohol, drank about 2/3 cup of it, and then vomited immediately. The patient was in a postprandial state, and he had had his last meal 4 hours before the presentation to the emergency department.

The patient had a history of depression without medication and chronic alcoholism. He appeared acutely ill and his temperature was $37.5^{\circ} \mathrm{C}$, blood pressure $100 / 60$ $\mathrm{mmHg}$, and pulse rate 98 beats/min. A physical examination revealed a dry tongue, oropharyngeal burns, alcohol breath odor, agitation, and decreased skin turgor. The

Copyright $\odot 2020$ Korean College of Helicobacter and Upper Gastrointestinal Research

(a) The Korean Journal of Helicobacter and Upper Gastrointestinal Research is an Open-Access Journal. All articles are distributed under the terms of the Creative Commons Attribution Non-Commercial License (http:// creativecommons.org/licenses/by-nc/4.0) which permits unrestricted non-commercial use, distribution, and reproduction in any medium, provided the original work is properly cited. 
laboratory findings included a white blood cell count of $27,190 / \mathrm{mm}^{3}$, hemoglobin level of $17.2 \mathrm{~g} / \mathrm{dL}$, and platelet count of $292,000 / \mathrm{mm}^{3}$. Immediate arterial blood gas analyses revealed metabolic acidosis $\left(\mathrm{pH} 7.288, \mathrm{PaCO}_{2} 25.3\right.$ mmHg, $\mathrm{PaO}_{2} 75 \mathrm{mmHg}, \mathrm{HCO}_{3} 11.8 \mathrm{mmol} / \mathrm{L}, \mathrm{SaO}_{2}$ 92.1\%). CRP level was $4.42 \mathrm{mg} / \mathrm{dL}$, and the rest of laboratory test results, including coagulation function and electrolytes, liver function and kidney function were normal.

Direct X-ray examinations of the abdomen and chest were normal. Because of his hoarseness, laryngoscope was done to reveal severe edema of epiglottis and vocal cord without evidence of airway obstruction. Contrast-enhanced chest CT was performed to rule out the possibility of pneumonitis and perforation of upper gastrointestinal tract, before performing esophagogastroduodenoscope (EGD). Extensive thickening of esophageal wall with paraesophageal infiltration was noted (Fig. 1A), and severe transmural wall thickening with multiple ulceration in the stomach was also revealed on the chest CT (Fig. 1B).

Fifteen hours after admission, the patient underwent the index EGD. During EGD, diffuse linear mucosal breaks with hemorrhagic erosion, erythema with swelling, and shallow ulcerations were observed in the entire esophagus. In addition, dark brown or grayish discoloration, severe swelling with edema, and multiple erosions were detected at gastric body and antrum. These findings were compatible with corrosive esophagitis and gastritis (Fig. 2). The severities of injuries were graded endoscopically according to Zargar's classification as IIA (esophagitis) and IIIA (gastritis), respectively. The patient was admitted to the intensive care unit (ICU) because of possibilities of respiratory distress, renal dysfunction and combined state of corrosive esophagitis and corrosive gastritis. The initial therapy consisted of intravenous administrations of proton pump inhibitor (pantoprazole $40 \mathrm{mg}$ intravenous [i.v.]), steroids (dexamethasone $5 \mathrm{mg}$ i.v.) and antibiotics (ceftriaxone $2 \mathrm{mg}$ i.v.) with main-
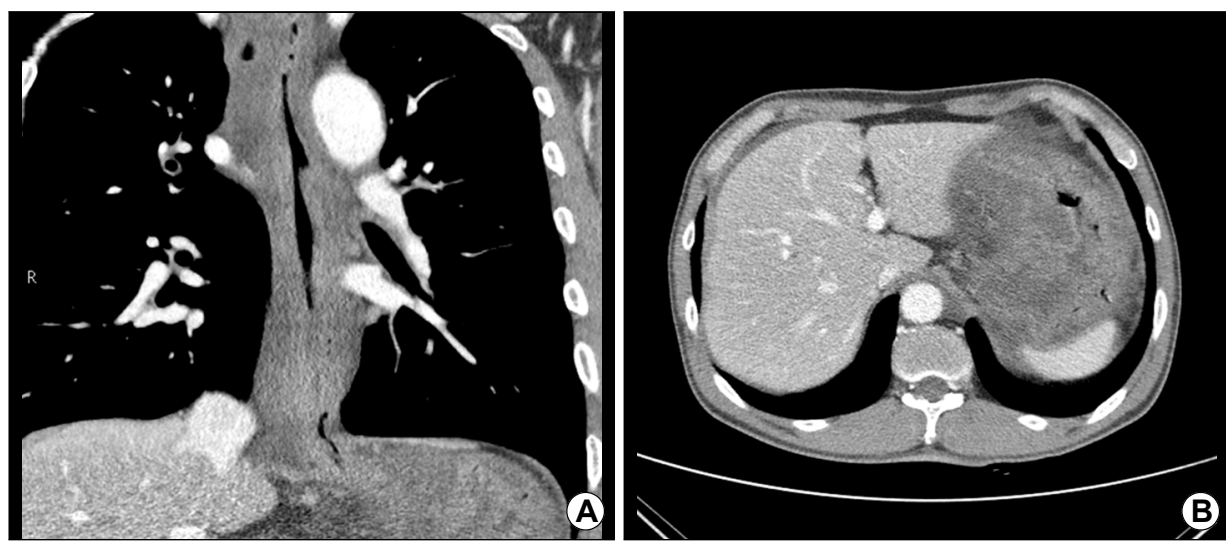

Fig. 1. (A) The contrast-enhanced chest CT image shows diffuse extensive esophageal wall thickening and paraesophageal infiltration. (B) Extensive wall thickening with multifocal deep ulceration in the stomach is shown, involving the gastroesophageal junction.
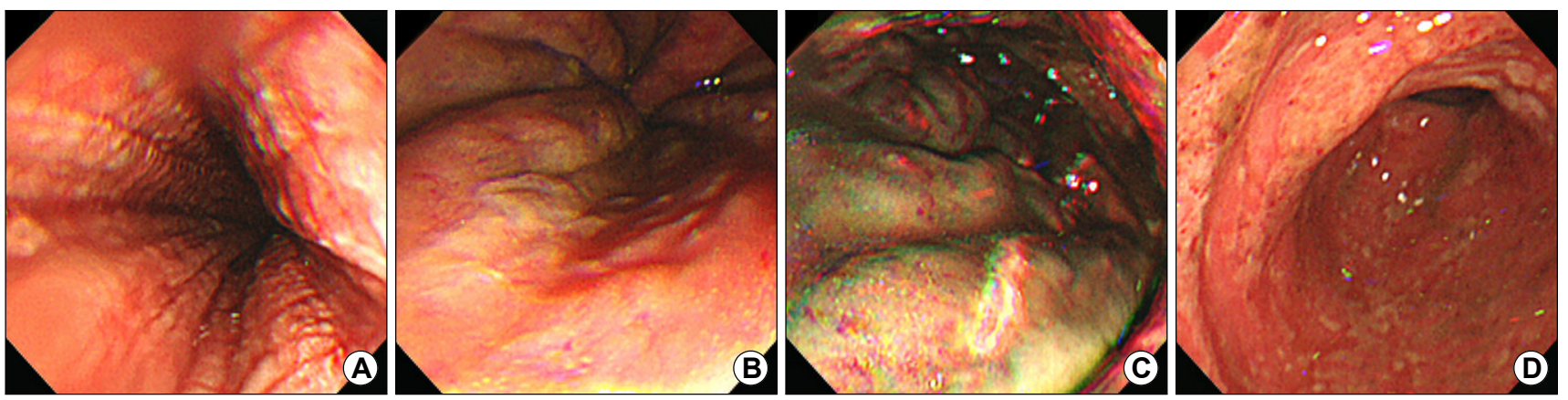

Fig. 2. The esophagogastroduodenoscopy images obtained 15 hours after admission shows corrosive changes of the esophagus and stomach. (A, B) Diffuse linear mucosal breaks with hemorrhagic erosion and erythema, and swelling is observed in the entire esophagus and gastroesophageal junction. (C) The gastric body shows dark brownish discoloration, severe mucosal swelling, and multiple erosions. (D) The gastric antrum has multiple hemorrhagic erosions, erythema, swelling, and shallow ulcers. 
taining fasting and total parenteral nutrition support. On the 3rd day after admission, the patient showed no air way distress or evidence of progression of laryngeal edema; therefore, steroid was tapered off after 8 days of administration. The patient showed stabilized vital signs without fever, so antibiotic treatment was discontinued on the 7 th day after admission.

On the 10th day after admission, follow up EGD was done (Fig. 3). Only minor erosive changes and signs of healing were detected in the esophagus. However, there was mild stricture noted at the gastroesophageal junction. On the other hand, there were still noted inflammation signs on the stomach and bulb of duodenum. As the patient complained of odynophagia on water ingestion, we did not proceed with the oral diet. Total parenteral nutrition and proton pump inhibitor infusion was maintained for additional 16 days. On the 26th day after admission, last EGD was done (Fig. 4). Esophageal damage was al- most completely healed, except remaining mild stricture at the gastroesophageal junction. Also, inflammatory mucosal change of gastric body, antrum and bulb of duodenum were in a much improved state. In addition, there was no abnormal finding regarding the small and large intestine in enhanced abdominal CT. Since odynophagia had abated as well, the patient was allowed to take sips of water from the 27th day after admission. After starting soft diet, there was no specific symptom complaint such as dysphagia or abdominal pain. After beginning oral diet, the patient underwent psychiatric therapy for chronic alcoholism and severe depressive mood before discharge. The patient was discharged on the 35th day after admission. After 1 month, he visited Chung-Ang University Hospital through outpatient clinic. The patient was in good condition without any significant symptom complaint.
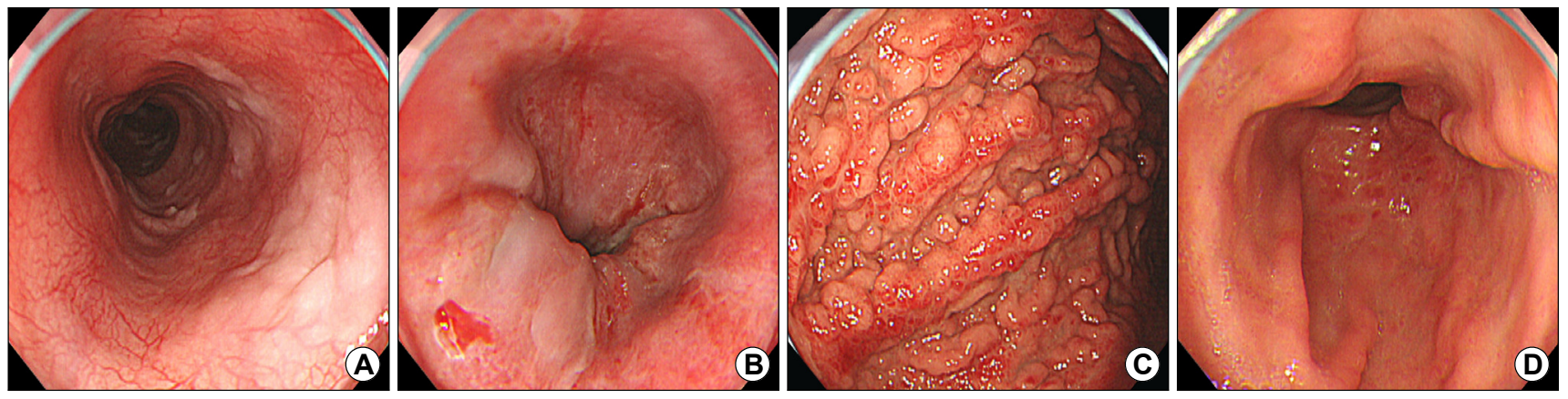

Fig. 3. (A) Esophagogastroduodenoscopy images obtained 10 days after admission. The erosions and edematous changes in the body of the esophagus have disappeared. (B) Mild degree of erythematous mucosal and minor erosive changes still remain at the gastroesophageal junction. (C) The swelling and erythematous changes of the gastric mucosa show a cobblestone appearance. (D) A subepithelial hemorrhage is also observed at the gastric body and antrum.
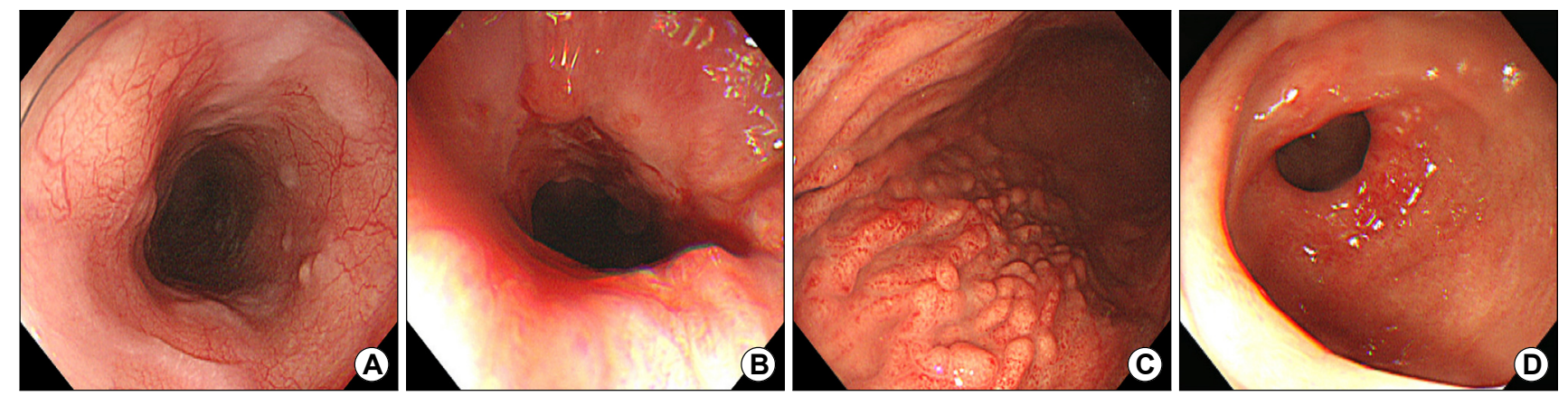

Fig. 4. Esophagogastroduodenoscopy images obtained 26 days after admission. (A, B) No mucosal abnormality is depicted in the body of the esophagus, except for the mild stricture formation at the gastroesophageal junction. (C, D) The erythema with swelling and subepithelial hemorrhage in the gastric body and antrum have substantially improved. 


\section{DISCUSSION}

Glutaraldehyde is a five-carbon dialdehyde $\left(\mathrm{C}_{5} \mathrm{H}_{8} \mathrm{O}_{2}\right)$ with a very high reactivity. ${ }^{2}$ As $2 \%$ glutaraldehyde solution is commonly used for disinfecting endoscopes, its toxic effect to human body has been reported as a few experiences in endoscopy units. Glutaraldehyde is colorless and acts as a strong irritant to skin, respiratory tract and eye. ${ }^{3}$ Glutaraldehyde vapor irritates the bronchial and laryngeal mucosa and it can lead to swelling of the mucosa. There is a report which described the toxic effect of glutaraldehyde, such as watering of eyes, rhinitis, dermatitis, respiratory difficulties, nausea and headache, experienced by several medical staffs in an endoscopy unit. ${ }^{4}$ In addition, it has also been reported that residual glutaraldehyde on the colonoscope after disinfection, could induce hemorrhagic colitis. There was a study about the effect of glutaraldehyde exposure in rats. According to this report, exposure to glutaraldehyde could produce toxic inflammation effect on submucosa near the gastroesophageal junction, leading to esophagitis or esophageal stricture. ${ }^{6}$ However, the damage to the upper gastrointestinal tract after ingestion of glutaraldehyde in human has not been reported before, as far as we know.

In this case, the patient drank a 10\% glutaraldehyde solution used for prevention of foot-and-mouth disease in pigs. This material is mainly available as acidic aqueous solutions (pH 3.0 4.0). ${ }^{7}$ Although caustic injury of gastrointestinal tract can be caused by either alkaline or acidic material, alkaline material accounts for most cases of caustic ingestion. ${ }^{8}$ Alkaline substances react with tissue proteins and fats, resulting in liquefactive necrosis. This leads to deeper penetration into tissues with a greater likelihood of transmural injury. On the other hand, acids are converted to acid proteins after it reacts with tissue proteins, leading to coagulation necrosis. The coagulated material at the surface prevents the transmural invasion of corrosive agent, reducing the penetrating depth of injury. ${ }^{910}$ However, it is known that according to the ingested amount or $\mathrm{pH}$ of causative materials, acidic substances can also cause full-thickness injury to the upper gastrointestinal tract. ${ }^{11}$ Traditionally, acids are known to cause more damage to the stomach, while alkalis mainly cause injury to the esophagus. In our case, the injury of stomach was transmural, and more severe than that of esophagus.

Caustic agents induce tissue necrosis, which leads to the damage of mucosa within a few seconds. On 1 or 2 days after the ingestion of alkaline agents, damage of the mucosa is accelerated by thrombosis in small vessels and the production of heat. ${ }^{12}$ In addition, scar formation begins at the third or fourth week and may continue for several months. As a result of these processes, stricture and shortening of the gastrointestinal tract can occur. Furthermore, shortening of the esophagus changes the lower esophageal sphincter pressure and aggravates gastroesophageal reflux, which gradually accelerates stricture formation. ${ }^{13}$ However, in this case, only mild esophageal stricture occurred after the event.

Endoscopy is recommended for evaluating the caustic injury especially during the first 12 to 48 hours of caustic ingestion. However, as the tissue becomes friable and as the risk of perforation increases, endoscopy is generally avoided from 5 to 15 days after caustic ingestion. ${ }^{14}$ The Zargar's classification is widely used to evaluate and classify corrosive injuries of the upper digestive tract. ${ }^{15}$ The injury can be graded from 0 to IV, and the higher grade means more severe degree of injury. This grading system could help the physicians to predict complications including stricture formation as well as systemic complications, respiratory failure, and long-term survival. ${ }^{16}$ Although the necessity or timing of follow-up endoscopy during hospitalization has not been clearly investigated, there are some reports where balloon dilatation or stent insertion can be performed due to stricture formation, in early chronic phase ( 3 weeks to 6 months). ${ }^{17,18}$ In addition, regular endoscopic examination during the long-term follow-up peroid is recommended, since the incidence of esophageal cancer increases after several decades from the event. ${ }^{17}$

Although there is no definite consensus on how long oral intake should be avoided, previous studies suggest that esophageal rest could decrease post-corrosive complications. Taking food by mouth can aggravate infection and inflammation of the damaged lesion, delay and complicate healing of the lesion. ${ }^{19}$ All things considered, the timing of 
resuming the oral diet should be determined by a comprehensive consideration of the severity of the tissue damage and the patient's overall condition. Oral intake can be started within days with antacid therapies in patients with relatively non-severe corrosive injuries. On the contrary, the timing of oral diet should be carefully determined in patients with more severe cases of damage (Zargar's grade II or III), and adequate nutritional support via parenteral route or nasoenteric tube is recommended in the early phase of injury. ${ }^{14}$ Stricture formation is one of the most important complications of corrosive damage to the esophagus. The existing literature does not strongly recommend corticosteroid administration for prevention of stricture formation, due to conflicting results and insufficient evidence to support this therapeutic approach. ${ }^{14}$ In this case, dexamethasone was only used for a short period due to severe epiglottitis with risk of airway obstruction. When severe edema and inflammation of larynx and epiglottis is suspected, steroid is often used to reduce edema and to secure the patency of the upper airway tract. This is a general approach for the early management of acute epiglottitis, although there is still lack of evidence whether the same approach should be taken in the case of corrosive epiglottic injury. ${ }^{20}$

We report the first case of corrosive esophagitis and gastritis due to accidental ingestion of glutaraldehyde, diagnosed through endoscopy in the early stage. The patient showed a favorable outcome with conservative treatment, showing minimal post-corrosive complication.

\section{CONFLICT OF INTEREST}

No potential conflict of interest relevant to this article was reported.

\section{ORCID}

$\begin{array}{ll}\text { Donghwan Jun } & \text { (D) https://orcid.org/0000-0002-7669-4374 } \\ \text { Hye-Jin Kim } & \text { (D) https://orcid.org/0000-0003-1037-8640 } \\ \text { Hyun Suk Lee } & \text { (D) https://orcid.org/0000-0002-3160-7222 } \\ \text { Hong Jip Yoon } & \text { (D) https://orcid.org/0000-0002-0859-7644 } \\ \text { Jae Yong Park } & \text { (D) https://orcid.org/0000-0001-6114-8920 } \\ \text { Beom Jin Kim } & \text { (D) https://orcid.org/0000-0002-0938-6697 }\end{array}$

Jae Gyu Kim (D) https://orcid.org/0000-0002-4841-9404

\section{REFERENCES}

1. Zwischenberger JB, Savage C, Bidani A. Surgical aspects of esophageal disease: perforation and caustic injury. Am J Respir Crit Care Med 2002;165:1037-1040.

2. Zissu D, Bonnet P, Binet S. Histopathological study in B6C3F1 mice chronically exposed by inhalation to glutaraldehyde. Toxicol Lett 1998;95:131-139.

3. Ballantyne B, Jordan SL. Toxicological, medical and industrial hygiene aspects of glutaraldehyde with particular reference to its biocidal use in cold sterilization procedures. J Appl Toxicol 2001;21:131-151.

4. Jachuck SJ, Bound CL, Steel J, Blain PG. Occupational hazard in hospital staff exposed to 2 percent glutaraldehyde in an endoscopy unit. J Soc Occup Med 1989;39:69-71.

5. Dolcé P, Gourdeau M, April N, Bernard PM. Outbreak of glutaraldehyde-induced proctocolitis. Am J Infect Control 1995; 23:34-39.

6. Isserow JA, Kumar N, Goldschmidt MH, Furth EE, Levine MS, Laufer I. Glutaraldehyde-induced esophageal injury. Histologic study of laboratory rats. Invest Radiol 1998;33:730-733.

7. Migneault I, Dartiguenave C, Bertrand MJ, Waldron KC. Glutaraldehyde: behavior in aqueous solution, reaction with proteins, and application to enzyme crosslinking. Biotechniques 2004:37:790-802.

8. Gumaste VV, Dave PB. Ingestion of corrosive substances by adults. Am J Gastroenterol 1992;87:1-5.

9. Lakshmi CP, Vijayahari R, Kate V, Ananthakrishnan N. A hospital-based epidemiological study of corrosive alimentary injuries with particular reference to the Indian experience. Natl Med J India 2013;26:31-36.

10. Chibishev A, Simonovska N, Shikole A. Post-corrosive injuries of upper gastrointestinal tract. Prilozi 2010;31:297-316.

11. Contini S, Scarpignato C. Caustic injury of the upper gastrointestinal tract: a comprehensive review. World J Gastroenterol 2013;19:3918-3930.

12. Ramasamy K, Gumaste VV. Corrosive ingestion in adults. J Clin Gastroenterol 2003;37:119-124.

13. Mutaf O, Genç A, Herek O, Demircan M, Ozcan C, Arikan A. Gastroesophageal reflux: a determinant in the outcome of caustic esophageal burns. J Pediatr Surg 1996;31:1494-1495.

14. De Lusong MAA, Timbol ABG, Tuazon DJS. Management of esophageal caustic injury. World J Gastrointest Pharmacol Ther 2017;8:90-98.

15. Zargar SA, Kochhar R, Mehta S, Mehta SK. The role of fiberoptic endoscopy in the management of corrosive ingestion and modified endoscopic classification of burns. Gastrointest Endosc 1991;37:165-169.

16. Cheng HT, Cheng CL, Lin CH, et al. Caustic ingestion in adults: the role of endoscopic classification in predicting outcome. BMC Gastroenterol 2008;8:31. 
17. Methasate A, Lohsiriwat V. Role of endoscopy in caustic injury of the esophagus. World J Gastrointest Endosc 2018;10:274-282.

18. Kim JH, Song HY, Kim HC, et al. Corrosive esophageal strictures: long-term effectiveness of balloon dilation in 117 patients. J Vasc Interv Radiol 2008;19:736-741.

19. Chibisev A. Post-corrosive late complications in esophagus and stomach--role of the esophageal rest. Med Arh 2010;64: 320-323.

20. Han KY, Song YJ, Ko HS, Kim JY, Kim JH, Shim BS. Acetic acid induced laryngitis. Korean J Otorhinolaryngol-Head Neck Surg 2008;51:1129-1133. 